\title{
Incision Lines: Active Movement as a Major Biodynamic Factor of Scarring
}

\author{
Andreas M. Skaria \\ Centre de Dermatochirurgie, University of Bern, Vevey, Switzerland
}

Extensive discussions on the direction of incision lines have been held in surgical literature and they are often controversially discussed. Various approaches have been described, and often it is not clearly defined whether the authors refer to incision or excision lines only. We therefore would like to comment on the importance of biodynamic principles mentioned in recent literature.

Langer was the first author to report on incision lines, which are presently named after him [1]. He developed a theory by applying a round punch on lying cadavers where he observed the resulting defects having an oval shape. He defined them as "Spaltrichtungen" or cleavage lines; i.e., a series of lines that seem to align themselves with the natural orientation of collagen fibers in the dermis. Most studies found that these lines lie in line to the underlying muscle fibers. As shown in Figure 1b, this does not entirely reflect reality. Pinkus [2] described folding lines in 1927, and Kraissl [3] discussed dynamic lines perpendicular to the underlying muscle in 1951. Lemperle et al. [4] mentioned main folding lines, and Borges [5] referred to the principle of relaxed skin tension lines, which are also lines perpendicular to the underlying muscles. The latter appears to have developed into an established principle in facial surgery to hide scars within the wrinkles of the face. The principle of relaxed skin tension lines seems to be less applicable to in- cision lines on the body due to higher mobility in relation to the articulations and absence of wrinkles perpendicular to the muscle.

Therefore, there is a wide spectrum of recommendations, some based on static considerations and others based on anatomical observations. All of them report that active movement and resulting tension have not been given due consideration.

In 1999, we published a recommendation considering these parameters in one of the main French standard textbooks on dermatology, based on the observation of incision lines in orthopedic surgery [6].

We hypothesize that perpendicular tension on a scar will lead to dehiscence, thus stimulating myofibroblasts [7]. Studies have shown that micromovements and tension are the main factors that stimulate myofibroblasts to produce collagen $[7,8]$. Hyperproduction of collagen leads to the development of hypertrophic scars. For this reason, immobilization of a scar is one of the main factors in preventing hypertrophy [8]. Bouffard et al. [8] have shown that stretch in line of a wound decreases collagen production and enhances transforming growth factor beta 1 expression. Thus, Kanevsky et al. [9], in their experiments on mice, confirmed that stretch in line of an incision can improve the outcome of scars [9]. They suggest that linear stretch minimizes perpendicu- karger@karger.com

(c) 2020 S. Karger AG, Basel

www.karger.com/drm

Karger!
Andreas M. Skaria

Centre de Dermatochirurgie, University of Bern

Rue de Lausanne 15

$\mathrm{CH}-1800$ Vevey (Switzerland)

E-Mail skaria@vtxnet.ch 


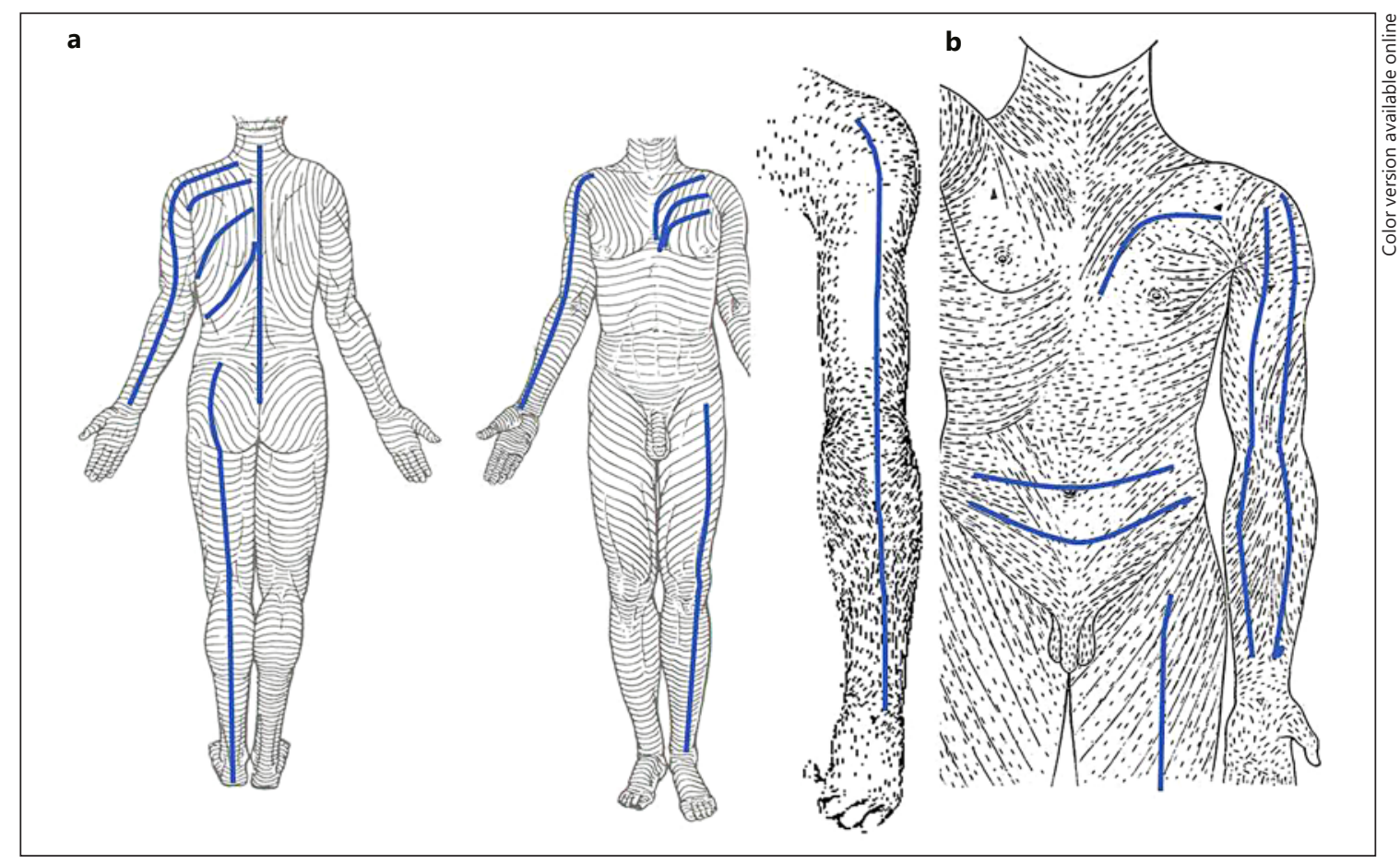

Fig. 1. The incision lines of Borges (a) and Langer (b) are mostly not directed in line with biomechanical tension. The incision or excision lines should be in line with biomechanical activity (blue lines).

lar tension across the wound and further promotes approximation of the wound edges. Studies by Paul [10], who measured tension on post-excisional scars on the lower limbs in patients, postulated the principle of biodynamic excisional skin tension (BEST) lines (Fig. 2). This confirms the stipulation on animal tests by Kanevsky et al. [9] in humans.

Sometimes, perpendicular tension is unavoidable, particularly when a scar is close to an articulation. In this case, tension on the scar should be kept as low as possible to prevent perpendicular tension, a lazy S- or Zplasty can redistribute tension forces and diminish the risk for dehiscence and atrophy/hypertrophy near the articulations or in large excisions. Tension should be maintained in both the line of the scar and direction of the articulation movement. It is known that most scars produced by orthopedists, even though placed on articulations, do not show hypertrophy and only rarely surgical wound dehiscence. When it does, it will resolve within a few months. In contrast, a scar perpendicular to joint movement will create major wound dehiscence and atrophy/hypertrophy depending on skin elasticity as previously shown $[6,8]$. On the trunk, the risk of wound dehiscence is less, except on the back. However, in the extremities, scars perpendicular to the deltoid

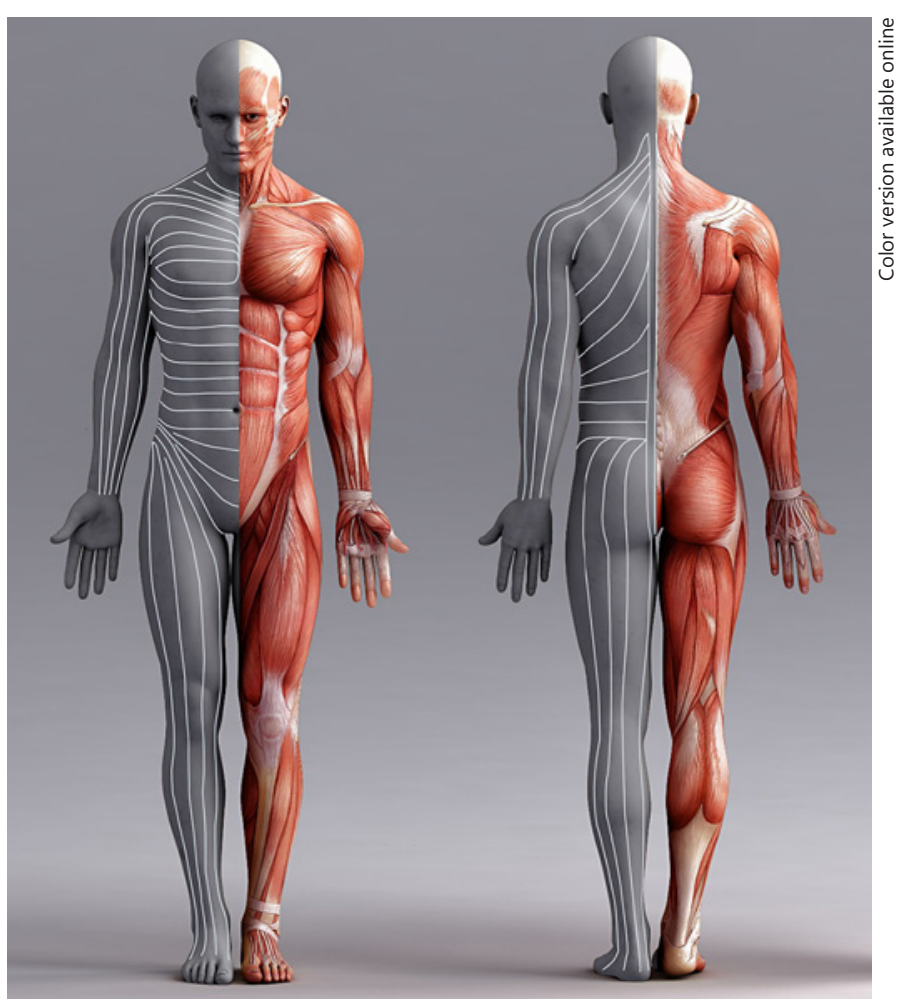

Fig. 2. This is an alignment with biomechanical tension lines as we have postulated in 1999 and that what Paul [10] calls BEST lines. 
muscle, Achilles tendon, or articulation are subjected to constant tension in the normal upright position and physical activity; therefore, Langer's and Borges' theory may not be applicable.

We should place scars in line with muscle contraction or joint movement. These excision lines should be called BEST lines, as Paul [10] stipulated in his study on lowerlimb excisions.

\section{Key Message}

The incision lines after Langer and Borges are not any more adapted to new concepts in Dermatosurgery because biomechanical principles were not taken into account.

\section{Disclosure Statement} close.

\section{References}

1 On the anatomy and physiology of the skin. I. The cleavability of the cutis. (Translated from Langer, K. (1861). Zur Anatomie und Physiologie der Haut. I. Uber die Spaltbarkeit der Cutis. Sitzungsbericht der Mathematischnaturwissenschaftlichen Classe der Kaiserlichen Academie der Wissenschaften, 44, 19.). Br J Plast Surg. 1978 Jan;31(1):3-8.

2 Pinkus F. Die normale Anatomie der Haut. In: Jadassohn J. Handbuch der Haut- und Geschlechtskrankheiten. 1927. p. 4-76.

3 Kraissl CJ. The selection of appropriate lines for elective surgical incisions. Plast Reconstr Surg. 1951 Jul;8(1):1-28.

4 Lemperle G, Tenenhaus M, Knapp D, Lemperle SM. The direction of optimal skin inci- sions derived from striae distensae. Plast Reconstr Surg. 2014 Dec;134(6):1424-34.

5 Borges AF. Relaxed skin tension lines (RSTL) versus other skin lines. Plast Reconstr Surg. 1984 Jan;73(1):144-50.

6 Skaria AM, Bezzola A, Salomon D. Principes de dermatologie chirurgicale. In: Saurat JH, editor. Dermatologie et infections sexuellement transmissibles. 3rd ed. Paris: Masson; 1999. p. 1116-24.

7 Tomasek JJ, Gabbiani G, Hinz B, Chaponnier C, Brown RA. Myofibroblasts and mechanoregulation of connective tissue remodelling. Nat Rev Mol Cell Biol. 2002 May;3(5):349-63.

8 Bouffard NA, Cutroneo KR, Badger GJ White SL, Buttolph TR, Ehrlich HP, et al. Tis- sue stretch decreases soluble TGF-beta1 and type-1 procollagen in mouse subcutaneous connective tissue: evidence from ex vivo and in vivo models. J Cell Physiol. 2008 Feb; 214(2):389-95.

9 Kanevsky J, Vorstenbosch J, Diaz-Abele J, Safran T, Prinz M, Tahiri Y, et al. Development and assessment of a cutaneous tissue stretch device as a novel scar therapy. Plast Aesthet Res. 2016;3(11):351-8.

10 Paul SP. Biodynamic excisional skin tension lines for excisional surgery of the lower limb and the technique of using parallel relaxing incisions to further reduce wound tension. Plast Reconstr Surg Glob Open. 2017 Dec; 5(12):e1614. 